\title{
The new jettison policy for the International Space Station
}

\author{
Nicholas L. Johnson* \\ Orbital Debris Program Office, NASA Johnson Space Center, NASA, 2101 NASA Parkway, Houston, TX 77058-3963, USA
}

\begin{abstract}
During more than seven years of operations by the International Space Station (ISS), approximately three dozen pieces of debris were released and subsequently cataloged by the U.S. Space Surveillance Network (SSN). The individual mass of these objects ranged from less than $1 \mathrm{~kg}$ to $70 \mathrm{~kg}$. Although some of these debris were separated from the ISS accidentally, some were intentionally cast-off, especially the larger items. In addition, small operational satellites are candidates for launch from the ISS, such as the TNS-0 satellite deployed from ISS in March 2005. Recently an official ISS Jettison Policy was developed to ensure that decisions to deliberately release objects in the future were based upon a complete evaluation of the benefits and risks to the ISS, other resident space objects, and people on the Earth. The policy identifies four categories of items which might be considered for release: (1) items that pose a safety issue for return on-board a visiting vehicle, (2) items that negatively impact ISS utilization, return, or on-orbit stowage manifests, (3) items that represent an EVA timeline savings, and (4) items that are designed for jettison. Some of the principal issues to be addressed during this evaluation process are the potential for the object to recontact the ISS within the first two days after jettison, the potential of the object to breakup prior to reentry, the ability of the SSN to track the object, and the risk to people on Earth from components which might survive reentry. This paper summarizes the history of objects released from ISS, examines the specifics of the ISS jettison policy, and addresses the overall impact of ISS debris on the space environment.
\end{abstract}

\section{Debris from space stations}

The release of debris from space stations has been a common occurrence for more than 30 years. The generation of debris onboard a space station is a natural consequence, but its accumulation can present a direct or indirect hazard to the crew as well as result in reduced productivity. Although it is normally preferable to dispose of debris via a logistics vehicle, the size of the debris could prevent its transfer to another vehicle or the nature of the debris could pose a health hazard to the space station crew. Hence, the jettison of debris into space, in special cases, can be the most viable option.

During three months of manned operations with the Soviet Salyut 4 space station in 1975 more than a

\footnotetext{
${ }^{*}$ Tel.: +1 281483 5313; fax: +1 2814835276

E-mail address: nicholas.l.johnson@nasa.gov
}

dozen debris from the orbital complex were detected and cataloged by the U.S. Space Surveillance Network (SSN). Salyut 6, the first long-duration Soviet space station housed crews for four years and in the process produced more than 100 new debris, whereas its successor, Salyut 7, was responsible for twice as many debris in a similar time interval. The Mir space station, which supported crews over a span of 14 years, created more than 300 cataloged debris, but its rate of release was significantly lower than its predecessor. By contrast, the amount of cataloged debris released from the International Space Station has to date been considerably less (Fig. 1).

Debris can be generated either deliberately or accidentally. Salyuts 6 and 7 and Mir possessed a special airlock which could be used for conducting experiments, launching small satellites, or ejecting debris into space. Even with Progress resupply vehicles almost constantly docked with Salyuts 6 and 7 , refuse removal via the small airlock was not uncommon. However, dumping debris through the 


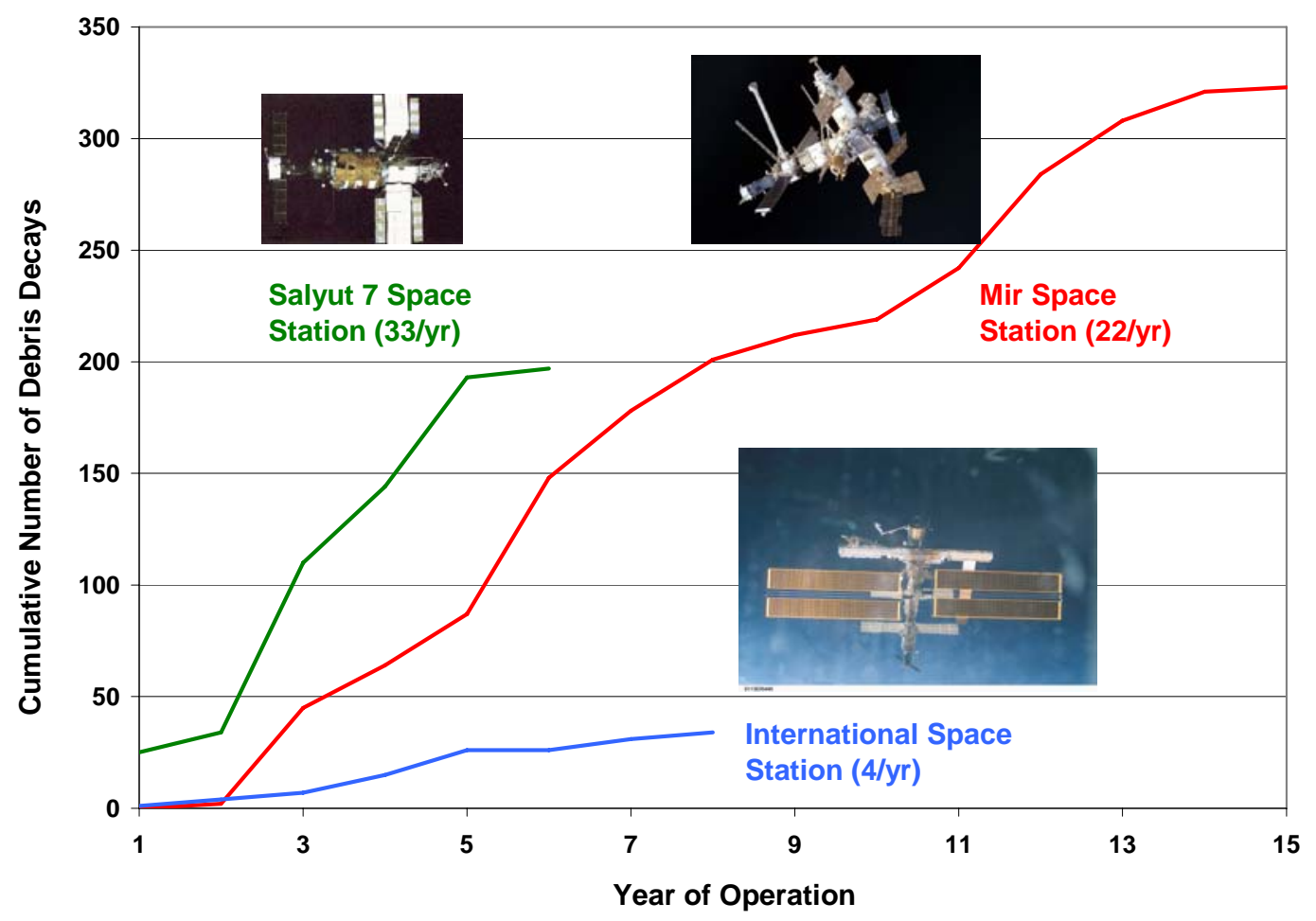

Fig. 1. Debris released from the past three space stations.

airlock appeared to be practiced less in the latter years of operations with the Mir space station.

During spacewalks debris, both small and large, are often thrown off the station for convenience, although sometimes tools unintentionally slip away. Such was the case in December 1998 when a slidewire carrier and a worksite interface were lost by the STS-88 crew while conducting an extravehicular activity (EVA) for ISS. These objects were large enough to be tracked by the U.S. SSN and were cataloged (U.S. satellite numbers 25564 and 25565). Three other objects were also released by STS-88 spacewalkers, one inadvertently (an insulation blanket) and two by design (antenna spools), although only the former was officially cataloged (Debris, 1999).

The sizes of debris vary dramatically from small, untrackable debris (normally less than $5 \mathrm{~cm}$ in diameter with today's SSN) to the 10-m diameter KRT-10 antenna which had to be kicked off the rear of Salyut 6 by a crew member when it failed to eject automatically. Several untrackable pieces of debris are known to have come off ISS, such as a small object in June 2003 (Fig. 2). Although debris of all sizes are of interest, the emphasis of the new ISS jettison policy is on objects which might pose the greatest risk to ISS, its stable of logistics vehicles (i.e., Space Shuttle, Soyuz, Progress, ATV, and HTV), and other operational satellites.

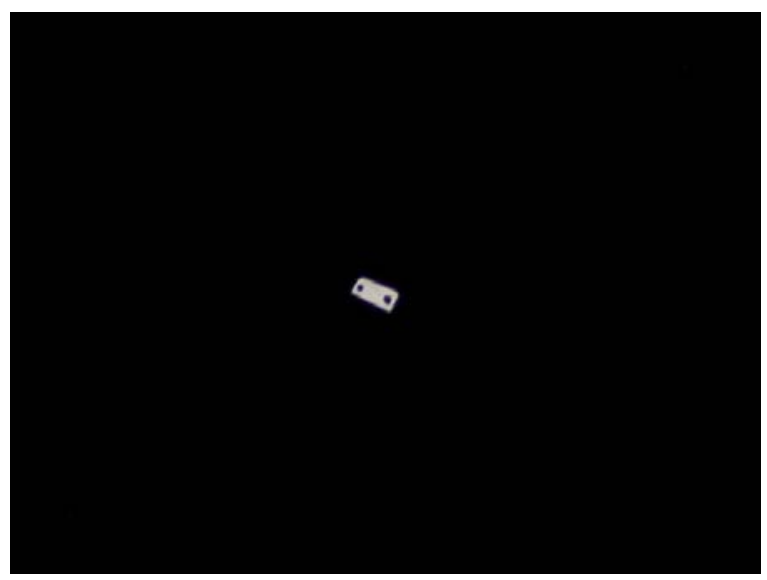

Fig. 2. Small debris observed from ISS in June 2003.

\section{ISS and debris}

As of 1 June 2006, 37 debris arising from ISS operations had been officially cataloged since the launch of the first station element in November 1998 (Table 1). Typically, debris experience rapid orbital decay and reenter the atmosphere within about one month. However, a total of five objects have taken more than 100 days to fall back to Earth. 
Table 1

ISS Debris from First Element Launch (20 November 1998) to 1 June 2006

\begin{tabular}{|c|c|c|c|c|c|}
\hline Int. Desig. & Sat. No. & Common Name & Release Date & Decay Date & Orbital Lifetime (days) \\
\hline 1998-067C & 25570 & ISS DEB & 7-Dec-98 & 14-Dec-98 & 7 \\
\hline 1998-069D & 25564 & STS 88 DEB (WIRE CARRIER) & 7-Dec-98 & 8-Apr-99 & 122 \\
\hline 1998-069E & 25565 & STS 88 DEB (SOCKET) & 7-Dec-98 & 24-Mar-99 & 107 \\
\hline 1998-067D & 25846 & ISS DEB & 29-May-99 & 18-Aug-99 & 81 \\
\hline 2000-053B & 26492 & STS 106 DEB & 11-Sep-00 & 20-Sep-00 & 9 \\
\hline 2000-053C & 26493 & STS 106 DEB & 11-Sep-00 & 25-Sep-00 & 14 \\
\hline 1998-067E & 26572 & ISS DEB & $18-O c t-00$ & 1-Nov-00 & 14 \\
\hline 2001-010B & 26723 & STS 102 DEB (PAD) & 12-Mar-01 & 7-Jun-01 & 87 \\
\hline 1998-067F & 26943 & ISS DEB & 8-Oct-01 & $10-$ Oct-01 & 2 \\
\hline 1998-067G & 26944 & ISS DEB & 8-Oct-01 & 18-Oct-01 & 10 \\
\hline 1998-067H & 26945 & ISS DEB & 8-Oct-01 & 19-Oct-01 & 11 \\
\hline 1998-067J & 26946 & ISS DEB & 8-Oct-01 & 17-Oct-01 & 9 \\
\hline 1998-067K & 26950 & ISS DEB & 8-Oct-01 & $12-O c t-01$ & 4 \\
\hline 1998-067L & 26951 & ISS DEB & 15-Oct-01 & 26-Oct-01 & 11 \\
\hline 1998-067M & 26952 & ISS DEB & $15-O c t-01$ & 26-Oct-01 & 11 \\
\hline $1998-067 N$ & 27166 & ISS DEB & 14-Jan-02 & 16-Jan-02 & 2 \\
\hline 1998-067P & 27167 & ISS DEB & 14-Jan-02 & 26-Feb-02 & 43 \\
\hline 1998-067Q & 27328 & ISS DEB & 25-Jan-02 & 6-Feb-02 & 12 \\
\hline 1998-067R & 27505 & ISS DEB & 23-Aug-02 & 4-Sep-02 & 12 \\
\hline 1998-067S & 27506 & ISS DEB & 23-Aug-02 & 3-Sep-02 & 11 \\
\hline 1998-067T & 27507 & ISS DEB & 23-Aug-02 & 4-Sep-02 & 12 \\
\hline 1998-067U & 27521 & ISS DEB & 23-Aug-02 & 11-Sep-02 & 19 \\
\hline 1998-067V & 27522 & ISS DEB & 23-Aug-02 & 11-Sep-02 & 19 \\
\hline 1998-067W & 27523 & ISS DEB & 23-Aug-02 & 12-Sep-02 & 20 \\
\hline 1998-067X & 27524 & ISS DEB & 23-Aug-02 & 12-Sep-02 & 20 \\
\hline 1998-067Y & 27539 & ISS DEB & 23-Aug-02 & 26-Oct-02 & 64 \\
\hline 1998-067Z & 28408 & ISS DEB & 3-Sep-04 & 12-Oct-04 & 39 \\
\hline 1998-067AA & 28409 & ISS DEB & 3-Sep-04 & $12-O c t-04$ & 39 \\
\hline 1998-067AB & 28410 & ISS DEB & 3-Sep-04 & 14-Oct-04 & 41 \\
\hline 1998-067AC & 28411 & ISS DEB & 3-Sep-04 & 3-Oct-04 & 30 \\
\hline 1998-067AD & 28412 & ISS DEB & 3-Sep-04 & 25-Jan-05 & 144 \\
\hline 1998-067AE & 28386 & ISS DEB & 3-Sep-04 & 5-Oct-04 & 32 \\
\hline 1998-067AF & 28635 & ISS DEB & 28-Mar-05 & 10-Apr-05 & 13 \\
\hline 1998-067AG & 28792 & ISS DEB & 18-Aug-05 & 24-Aug-05 & 6 \\
\hline 2000-078B & 28896 & FPP & 7-Nov-05 & 25-Feb-06 & 110 \\
\hline 2005-035C & 28933 & SUITSAT & 3-Feb-06 & (not yet decayed) & 118 \\
\hline \multirow[t]{3}{*}{ 2005-035D } & 28934 & SUITSAT DEB & 6-Feb-06 & 20-Mar-06 & 42 \\
\hline & & & & Total Object days & 1347 \\
\hline & & & & Total Object years & 3.69 \\
\hline
\end{tabular}

Total: 37 Debris

*Does not include TNS-0 spacecraft released from ISS on 28 March 2005 (lifetime $=155$ days)

*Does not include Kolibri spacecraft released from Progress M1-7 after separation from ISS

Fig. 3 illustrates the orbital decay histories of six objects which were released during an EVA on 3 September 2004. Five of the objects were antenna covers (three small and two large), all of which reentered within six weeks. The sixth object was a 70$\mathrm{kg}$ aluminum container which had been used to transport an important replacement part to ISS. Due to its smaller area-to-mass ratio, the container remained in orbit for nearly five months (144 days). In addition to these six debris, at least seven more objects (connector caps and towels) were cast off, but these were too small for the SSN to track and catalog. These debris also probably reentered within a month of release.
On 7 November 2005 the ISS Expedition 12 crew performed an EVA to disconnect and jettison the Floating Potential Probe (FPP), a 23-kg instrument installed nearly five years earlier to measure charging in the vicinity of the large solar arrays. Unfortunately, the device was not designed for long-term attachment to ISS (its task was completed in 2001) and during the ensuing years had become loose. Plans to dispose of the FPP in a Progress resupply spacecraft or to return it to Earth in a Space Shuttle were shelved due to the poor condition of the FPP and other considerations. After release the FPP quickly fell away from ISS and reentered on 25 February 2006 after 110 days (Fig. 4). 


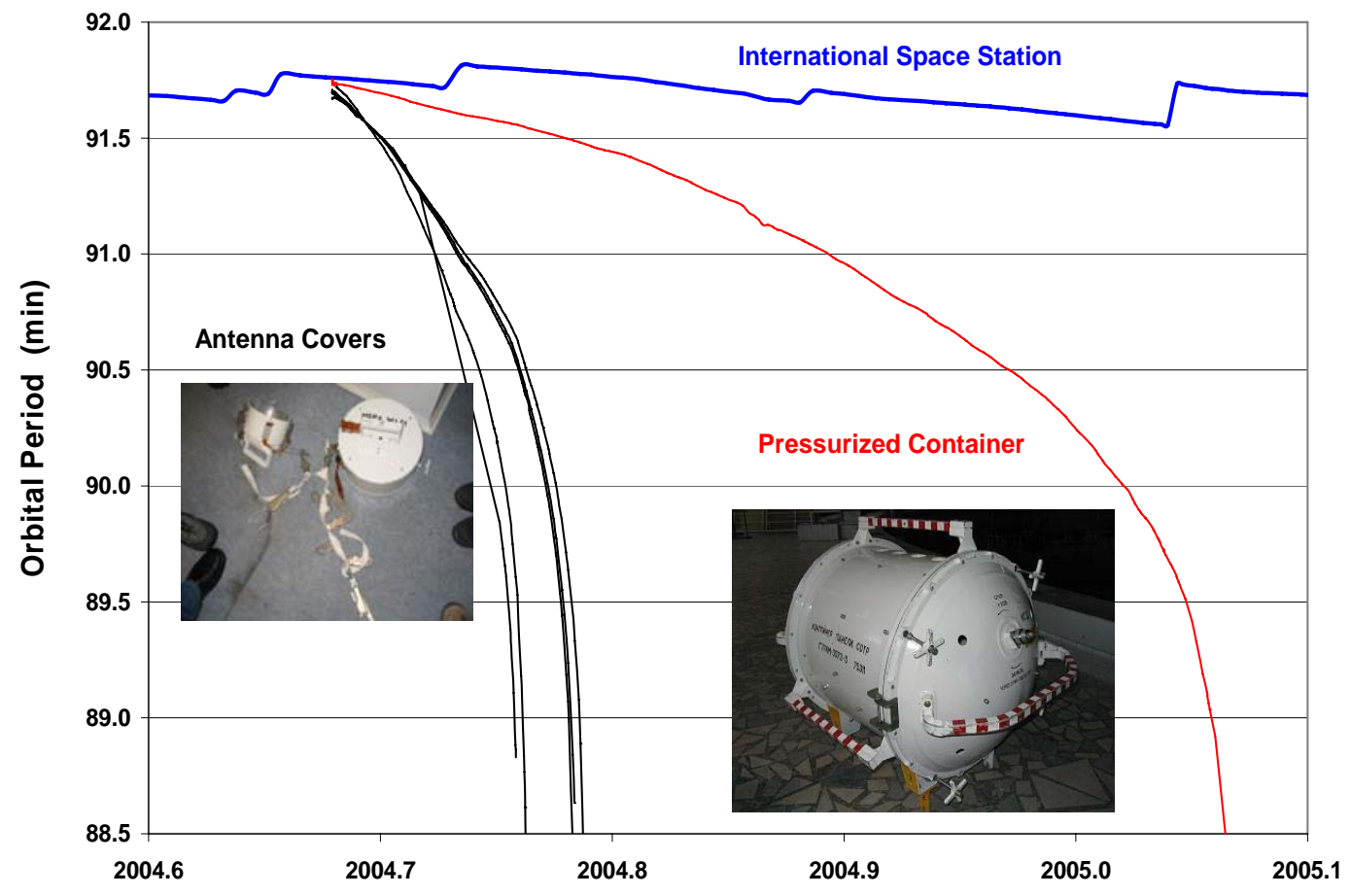

Fig. 3. Decay of tracked debris released from ISS in September 2004.

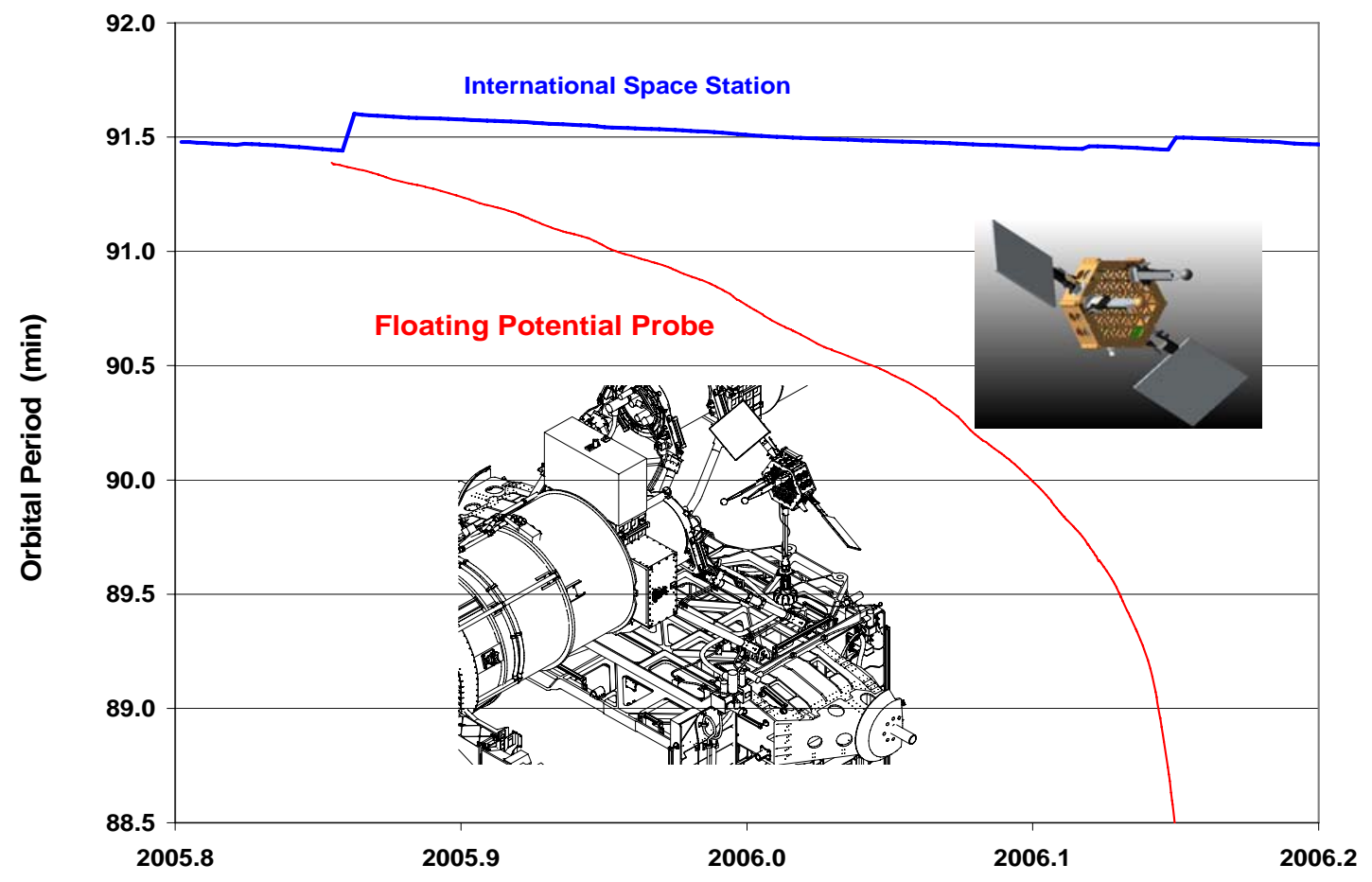

Fig. 4. Decay of Floating Potential Probe from ISS. 
Most EVAs do not involve the jettison of large objects from ISS, but they often result in small objects being cast off. During an EVA performed by the ISS Expedition 10 crew on 26 January 2005, a total of 20 objects were released: 16 electrical caps and four covers (Fig. 5). These items ranged in mass from 25 to 50 grams each and in size from 6 to $7 \mathrm{~cm}$. None were tracked and cataloged by the U.S. SSN, and all probably reentered rapidly.
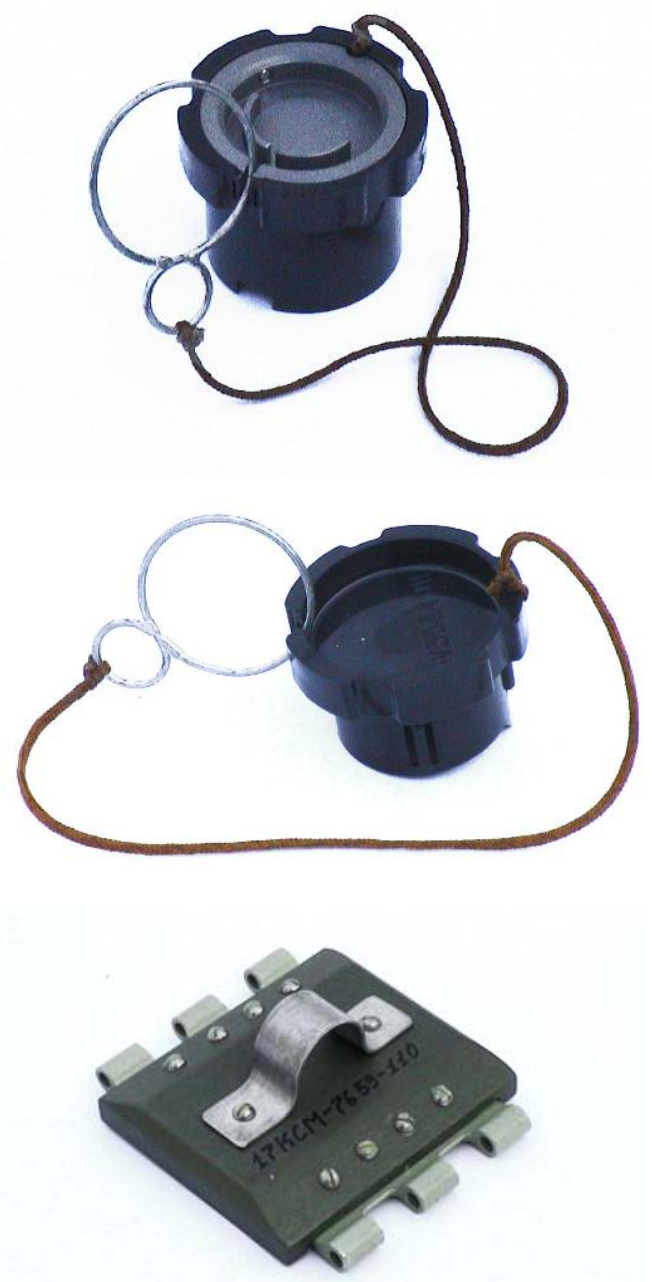

Fig. 5. Typical small objects released during ISS EVAs.

One of the most unusual objects jettisoned from ISS was a 4-year-old Russian Orlan M EVA suit. Instead of loading the used suit into a Progress vehicle for disposal, the ISS crew equipped it with a transmitter and dubbed it Radio Skaf (Fig. 6). The release occurred on 3 February 2006 during the second EVA for the Expedition 12 crew (Fig. 7). At the time of this COSPAR Scientific Assembly, the suit remains in Earth orbit but is anticipated to reenter the atmosphere later this summer.

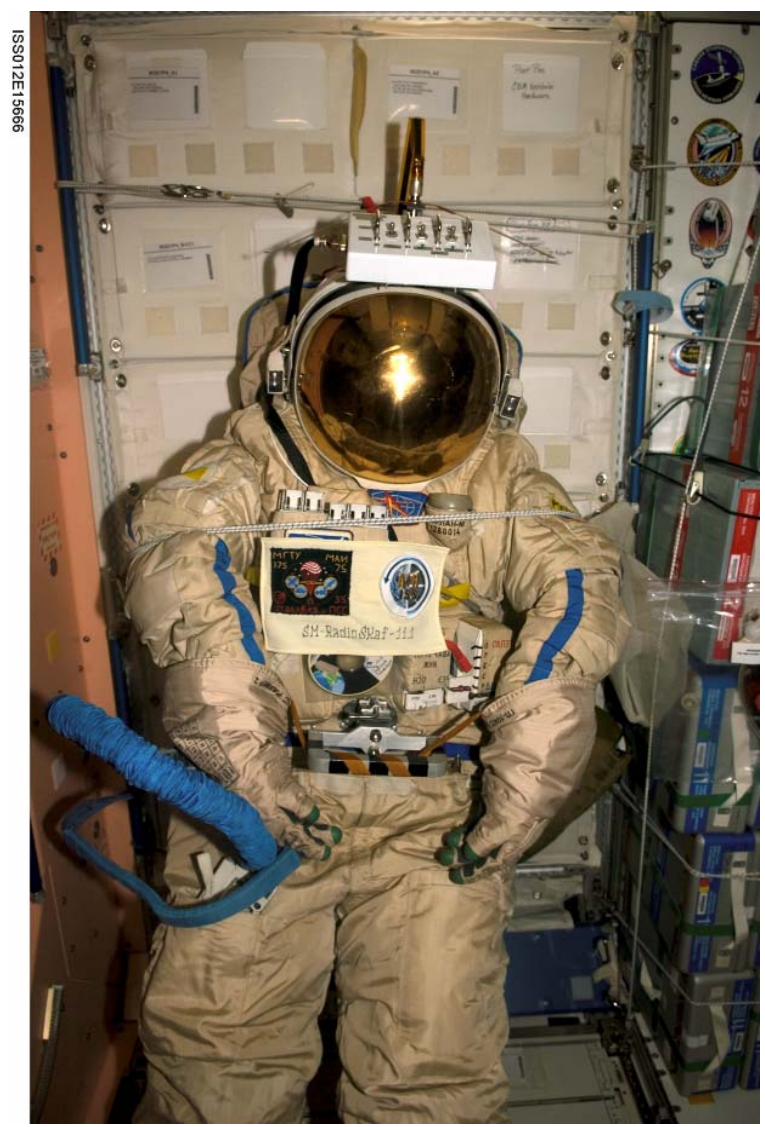

Fig. 6. Suitsat before release from ISS.

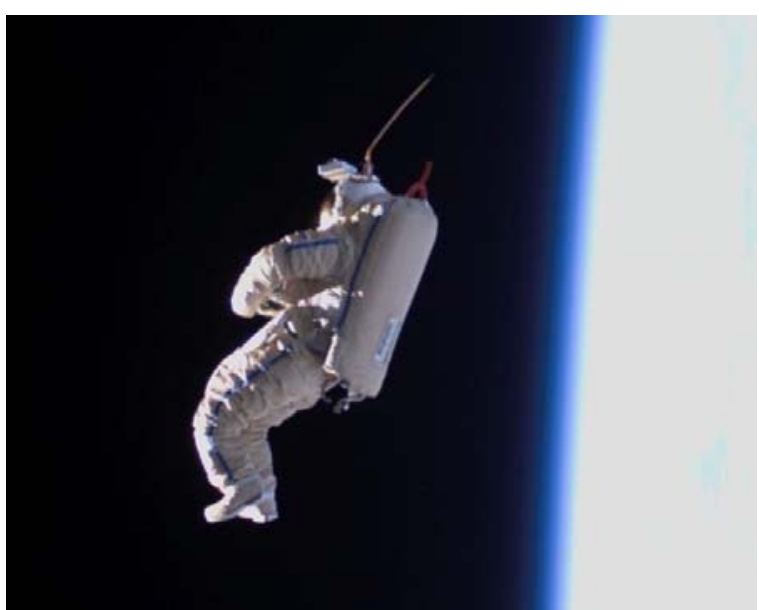

Fig. 7. Suitsat after release from ISS in February 2006.

\section{A jettison policy for ISS}

Informal discussions on guidelines for intentionally jettisoning large items from ISS began at the NASA Johnson Space Center (JSC) by 2002. The impetus for the exchanges was the recognition that (1) refuse was 
already accumulating within ISS, creating difficulties for the crew (Fig. 8), and (2) some significant components on the exterior of ISS needed to be removed in the future. Following the loss of Space Shuttle Columbia in February 2003, and the immediate cessation of shuttle flights, the debris situation onboard ISS worsened without the opportunity to routinely remove tons of debris via the space transportation system (Fig. 9).

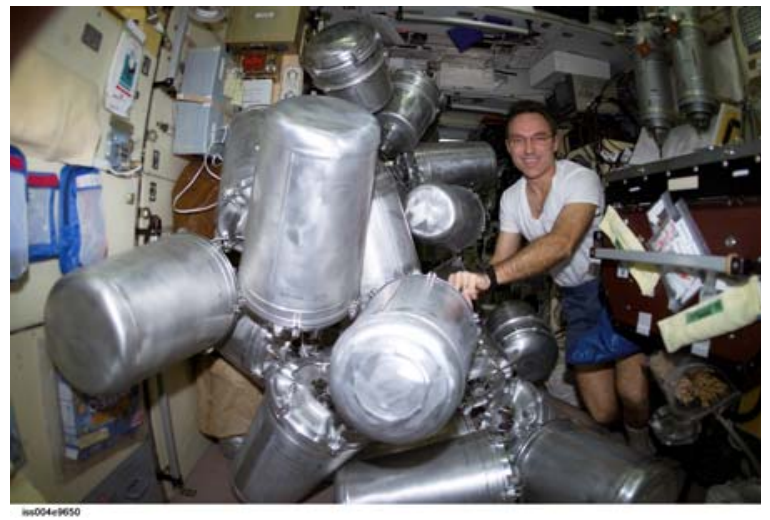

Fig. 8. Inside ISS, March 2002.

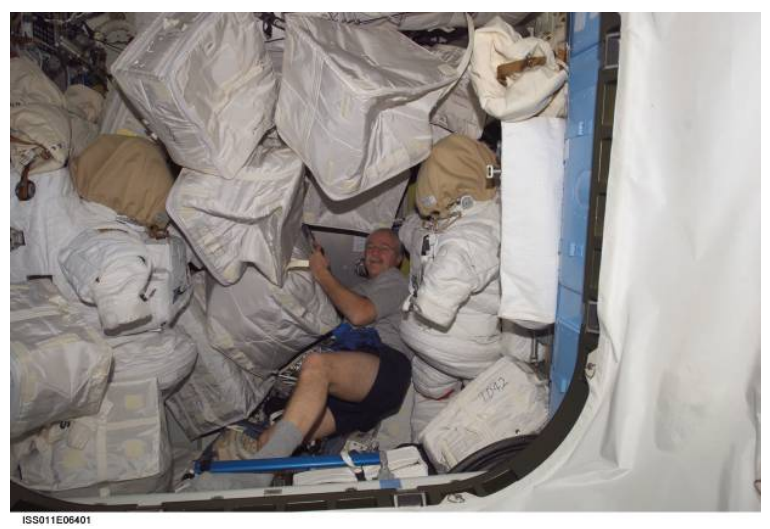

Fig. 9. Inside ISS, May 2005.

Following the release of the moderate-size transport container during the EVA of 3 September 2004 (see previous section), the ISS Program Office at JSC undertook an effort to develop a wide-ranging jettison policy for ISS. From the beginning, the paramount principle of the draft policy was that the jettison of objects from ISS should be strictly limited to situations for which alternative disposal options are not acceptable due to physical limitations or safety concerns. In particular, the safety of the crew, the station, other objects in orbit, and people on Earth must be addressed and promoted to the greatest extent possible. Furthermore, any ISS jettison policy must be compliant with NASA, U.S., and international guidelines for the mitigation of orbital debris.

The draft jettison policy foresees four specific conditions for which release authority might be granted:

(1) the return of an object on a logistics vehicle, crewed or robotic, is not possible or would present a greater risk than jettison of the object;

(2) the object negatively impacts ISS utilization;

(3) the return of an object onboard would result in a significant EVA task time increase; or

(4) the object is designed for jettison, e.g., launch of a small satellite.

In evaluating a proposal for approval to jettison an object, several criteria will be applied. First and foremost, the jettison operation should not pose a collision risk to either the ISS or to any visiting vehicle. Normally, objects should be ejected in a retrograde direction to accelerate separation between the object and ISS and to lessen total orbital lifetime.

Collision risk concerns are typically divided into two periods of interest: during the first few minutes and during the first few days after release. In the former case, the direction and speed of the release should be such to ensure that the object will not strike a portion of the ISS complex during its initial outward bound trajectory. This consideration is necessary since it is not always possible to eject an object from the aft-most position of ISS (with respect to the velocity vector at the time of release). Careful attention must be paid to the ability of the crew to release the object within a predetermined direction cone and with a minimum relative speed.

Fig. 10 shows the Early Ammonia Servicer (EAS) mounted on the exterior of ISS. This large object is a future jettison candidate, in part, due to the fact that it is no longer essential and cannot be certified as safe beyond 2007. Experienced EVA personnel have already demonstrated in test facilities on the ground their ability to handle and to carefully release such a large object with sufficient velocity (Fig. 11). 


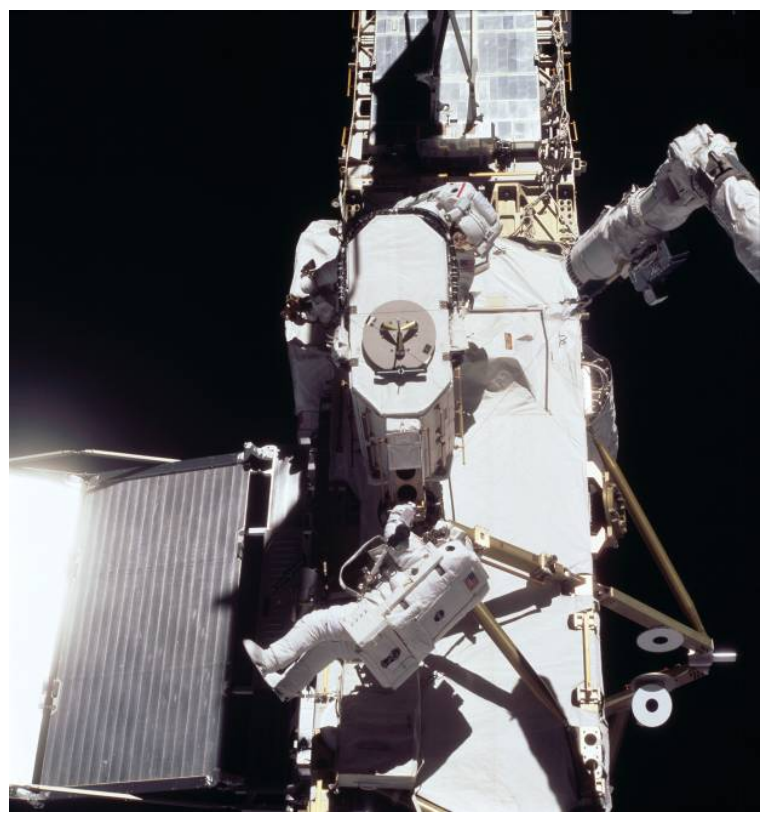

Fig. 10. Early Ammonia Servicer (EAS) on ISS.

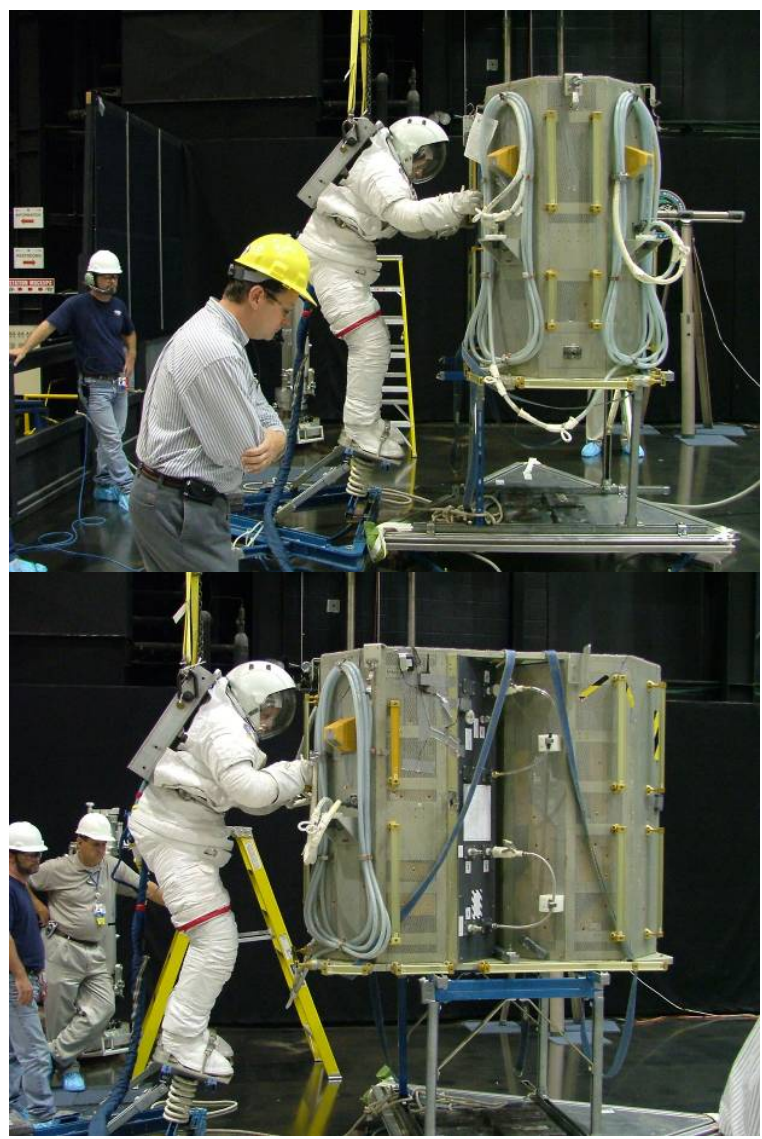

Fig. 11. Testing techniques for the potential release of EAS.
Once the object has safely cleared ISS, it is possible, in some cases, for the object to return to the vicinity of ISS and to pose a later collision risk. Detailed analysis of the relative ballistic coefficients and trajectories of the object and of ISS must be undertaken to evaluate potential close approaches during the period of up to 72 hours after release. Since most objects are not spheres and might be tumbling, their ballistic coefficients cannot be known with certainty prior to release. Most objects will decay faster than ISS, and, hence, will quickly fall below the altitude of the space station.

In the event that a released object still transits ISS altitudes after 2-3 days, tracking data from the U.S. SSN would permit routine conjunction assessments, a process now performed three times per day. In the highly unlikely case that a close approach were predicted, ISS could perform a collision avoidance maneuver. However, a jettison plan should not require such an avoidance maneuver. Furthermore, a jettison should be avoided during the independent flight of a crewed or robotic vehicle to or from ISS.

To support conjunction assessments, another criterion has been proposed that the released object consist of sufficient size and materials to be trackable by the SSN. To the greatest extent possible, small objects, such as connector caps, should be bagged and jettisoned together. This action not only will reduce the total number of objects released but also will increase the trackability of the items.

To be compliant with accepted orbital debris mitigation guidelines, the following additional criteria have been proposed:

(1) the object should not pose a fragmentation risk prior to reentry in excess of 1 in 10,000;

(2) no object should remain in Earth orbit for more than 25 years;

(3) the total object-time product for ISS jettisoned debris should be less than 100 object-years; and

(4) the risk of human casualty from the reentry of a jettisoned object should not exceed 1 in 10,000 .

From the above, it follows that, if possible, the object should be fully passivated before release. Likewise, Table 1 clearly indicates that most released objects have very short orbital lifetimes and that the total object-time product for all trackable objects from ISS to date is very low, i.e., less than 4 object-years. Explicit reentry risk assessments were performed for the aforementioned equipment carrier and the FPP. Neither object was assessed to pose any human casualty risk following reentry.

Fortunately, the region of space employed for human space flight (typically below $400 \mathrm{~km}$ altitude) also 
corresponds to a region of low spatial density, i.e., the number objects per unit volume. In addition, the orbital lifetimes of debris in this region are very short, usually measured in terms of weeks or months. Consequently, the release of debris from ISS has only a transitory and largely negligible effect on the environment.

\section{Summary}

The release of debris from space stations and arising from human space operations in general has been commonplace for more than 40 years. Due to the relatively low altitude of such activities, all debris are relatively short-lived and have no long-term effect on the near-Earth space environment.

Recognizing the occasional need to jettison items, the ISS program has been developing a formal jettison policy. However, logistics vehicles will remain the primary means of removing refuse and non-functional items from ISS. The jettison of debris will be restricted to special occasions dictated by safety and/or operational needs. Moreover, the approval process for release of objects from ISS will be comprehensive and will emphasize the safety of the crew, ISS, visiting vehicles, other space objects, and people on Earth. Formal adoption of the ISS jettison policy is anticipated in the very near future.

\section{References}

"Debris from STS-88 EVAs, The Orbital Debris Quarterly News, Volume 4, Issue 1, NASA Johnson Space Center, January 1999, p. 8 (www.orbitaldebris.jsc.nasa.gov/newsletter/newsletter.html) Guidelines and Assessment Procedures for Limiting Orbital Debris, NASA Safety Standard 1740.14, August 1995 (www.orbitaldebris.jsc.nasa.gov/library/references.html)

IADC Space Debris Mitigation Guidelines, IADC-02-01, InterAgency Space Debris Coordination Committee, October 2002 (www.iadc-online.org)

U.S. Government Orbital Debris Mitigation Standard Practices, February 2002 (www.orbitaldebris.jsc.nasa.gov/library/references.html) 